\title{
Sistema de produção de bovinos de corte e ecoturismo: exemplo da fazenda São José no Pantanal do Mato Grosso do Sul
}

\author{
Kennyson Alves de Souza ${ }^{1}$, Maribel Velandia Valero ${ }^{2}$, Ana Guerrero ${ }^{2}$, Carlos Sañudo ${ }^{3}$, Ivanor \\ Nunes do Prado ${ }^{4} *$ \\ ${ }^{I}$ Aluno de doutorado do Programa de Pós Graduação em Zootecnia da Universidade Estadual de Maringá. \\ ${ }^{2}$ Aluno de pós doutorado do Programa de Pós Graduação em Zootecnia da Universidade Estadual de Maringá. \\ ${ }^{3}$ Professor catedrático da Universidad de Zaragoza - Espanha. \\ ${ }^{4}$ Professor do Departamento de Zootecnia da Universidade Estadual de Maringá. Pesquisador 1A do CNPq. \\ *Autor para correspondência. E-mail: inprado@uem.br.
}

RESUMO. A fazenda São José está localizada no pantanal do Mato Grosso do Sul, próximo a cidade de Aquidauana. Esta propriedade tem como atividades o eco-turismo e a pecuária de corte. No eco-turismo destaca-se a visita aos animais silvestres (aves e mamíferos) e ao rio Miranda. No entanto, a fonte essencial de recursos para manter a fazenda em atividade é a bovinocultura de corte. A bovinocultura de corte está baseada essencialmente na exploração de bovinos da raça Nelore. Os índices produtivos da fazenda São José estão acima dos índices de sistemas extensivos e próximos aos níveis de propriedades mais produtivas. Neste ano o proprietário da fazenda está iniciando um projeto interessante com o cruzamento de algumas vacas com um reprodutor da raça Pantaneira. Este trabalho visa explorar a adaptação da raça no eco-sistema e aumentar a sua produção com a introdução da raça Nelore. Outra atividade desenvolvida na fazenda é a produção de leite com uso de vacas mestiças bem adaptadas ao clima típico da região. No entanto, a produção de leite está abaixo da média do sistema de produção com gado girolando.

Palavras chave: Animais silvestres, bovinos, pantanal, sistema extensivo, turismo

\begin{abstract}
The São José farm is located in Pantanal of Mato Grosso do Sul, near the Aquidauana city. This property has activities like eco-tourism and beef cattle. In ecotourism there is the visit to the wildlife (birds and mammals) and the river Miranda. However, the essential source for resources to keep the farm in activity is the beef cattle. The beef cattle is essentially based on the exploitation of Nellore cattle. The production rates of São José farm are above the system indexes extensive and close to levels more productive properties. This year the farm owner is starting an interesting project with the crossbreeding of some cows with a player of Pantaneira breed. This paper aims to explore the adaptation of breed in eco-system and increase its production with the introduction of Nellore. Another activity developed on the farm is the production of milk with use of crossbred cows adapted to the typical climate of the region. However, the production of milk is below average production system with Girolando cattle.
\end{abstract}

Keywors: wildlife animals, bovines, pantanal, extensive system, tourism

\section{Production of beef cattle and ecotourism: São José property in Mato Grosso do Sul Pantanal}

\section{Introdução}

A região do pantanal do Mato Grosso do Sul sempre foi caracterizada pela sua beleza intrínseca e pela exploração extensiva de bovinos de corte (ANUALPEC, 2014). No entanto, no final do século passado e início deste século, algumas modificações estão ocorrendo, sobretudo, na exploração mais racional do ecosistema da região. Desta forma, a integração do sistema de produção extensivo de gado de corte e implantação de fazendas como refúgios ecológicos está ocorrendo de forma significativa. Vários são os exemplos desta integração. Além do mais, esta integração é necessária para 
manutenção dos dois sistemas. Segundo o proprietário da Fazenda São José não seria possível manter um sistema sem a interação com o outro sistema. Sua explicação é simples "um único sistema são seria possível em função dos altos custos e baixa remuneração. Assim, a fazenda não seria auto sustentável".

\section{Localização geográfica da fazenda São José}

A fazenda São José está localizada no município de Aquidauana, no Pantanal do Mato Grosso do Sul (Foto 1).

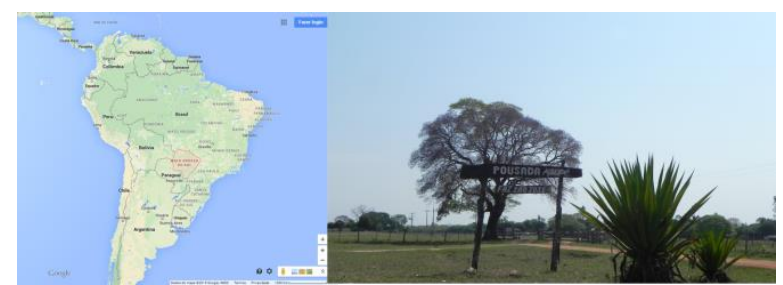

Foto 1. Localização da fazenda São José

O clima da região é tropical úmido com verão chuvoso e inverno seco. A temperatura média anual é de $25^{\circ} \mathrm{C}$ e umidade relativa de $82 \%$, mas pode ocorrer temperatura abaixo de $10^{\circ} \mathrm{C}$.

A quantidade de chuva varia entre $1.000 \mathrm{e}$ $1.400 \mathrm{~mm}$ ao ano. O período de cheia está entre janeiro e março. O período de vazante está entre os meses de abril e junho. Entre os meses de julho a setembro ocorre o período seco. As chuvas estão concentradas entre os meses de outubro a dezembro de cada ano.

\section{Caracterização e atividades da fazenda São José}

A fazenda São José explora o turismo ecológico e a produção semi extensiva de gado de corte. As atividades de ecoturismo da fazenda São José são caracterizas por exploração semi extensiva de bovinos de corte, caminhadas na mata, passeios a cavalo, explorações fotográficas, visualização de animais que revela a beleza da região.

\section{Sistema ecológico}

Na fazenda São José pode-se observar alguns mamíferos e pássaros da região. Os animais mantidos na natureza têm uma interação muito grande com o sistema de produção da fazenda. De fato, estes animais silvestres fazem parte da manutenção do sistema de respeito à ecologia do pantanal (Foto 2).
A Exploração racional dos animais silvestres faz parte do projeto de turismo ecológico mantido pela administração da fazenda. Assim sendo, o proprietário tem como maior a preservação racional dos animais que habitam a região.

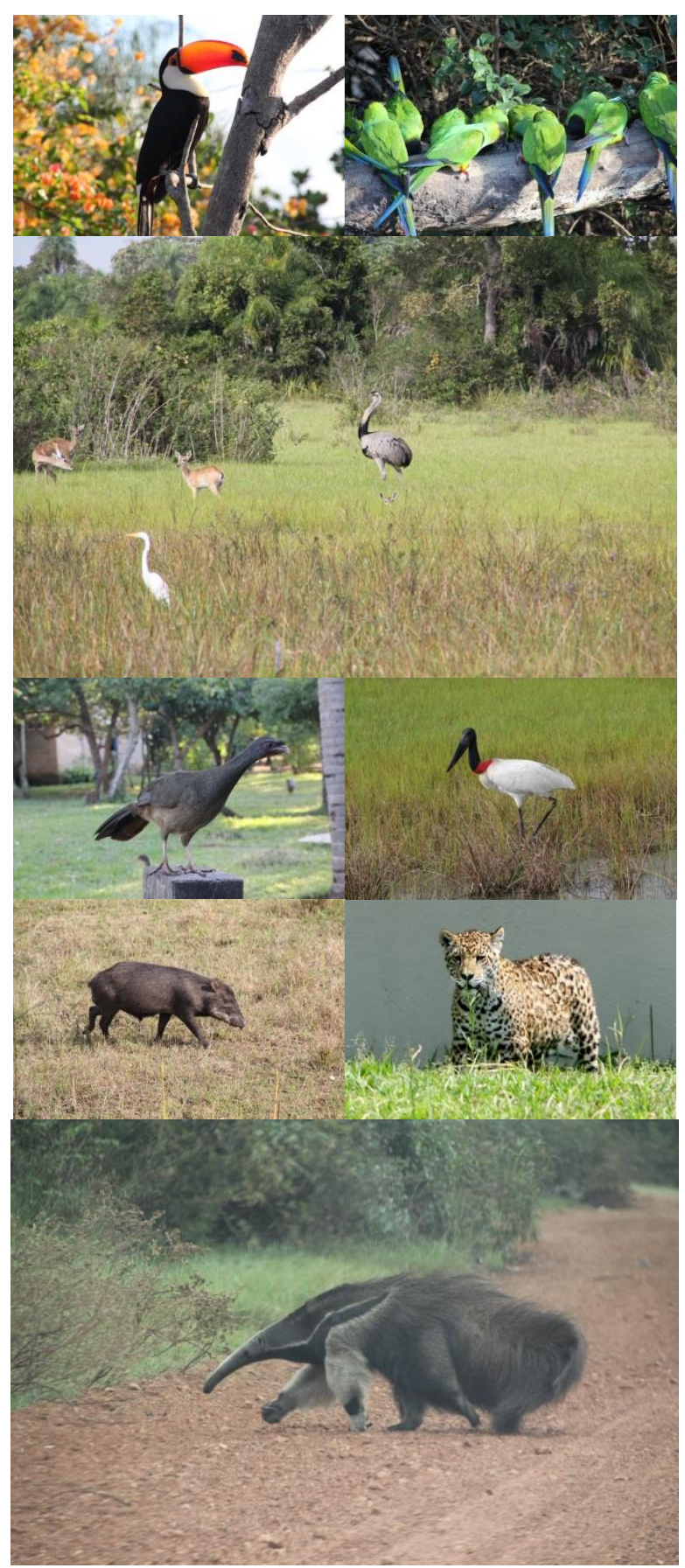

Foto 2. Algumas espécies animais existentes na fazenda São José.

No entanto, em determinados casos alguns felinos podem atacar o rebanho existente. Segundo o proprietário este é o preço que tem que pagar para viver em consonância com a natureza. $\mathrm{Na}$ realidade, este processo de integração da produção de bovinos de corte no 
pantanal do Mato Grosso trouxe alguns inconvenientes com o desmatamento da região. Assim sendo, os animais predadores necessitam sobreviver em um habitat que está sendo ocupado pela exploração racional de gado de corte. No entanto, segundo o próprio dono da propriedade está consciente da problemática existente entre a produção de gado no pantanal e ataque dos predadores.

Por outro lado, os visitantes têm, também, a possibilidade de visitar o rio Aquidauana, assim como, exercer uma atividade de pesca esportiva (Foto 3).

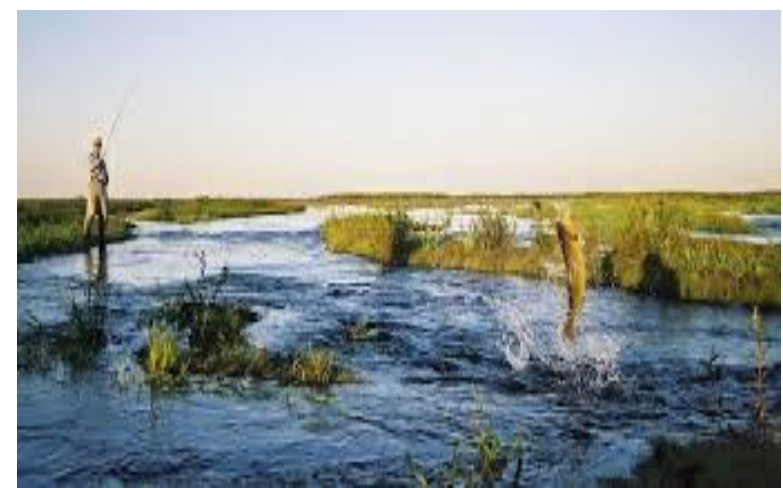

Foto 3. Pesca esportiva no rio Aquidauana.

\section{Sistema de produção de bovinos da fazenda São José}

A produção de bovinos na fazenda São José é realizada em dois sistemas: produção de leite e produção de carne. Desta forma, vamos discutir os dois exemplos de forma separados.

\section{Produção de leite}

Para a produção de leite utiliza-se um sistema de exploração familiar. As vacas usadas neste sistema são de baixa produção e muito bem adaptada na região (Foto 4).

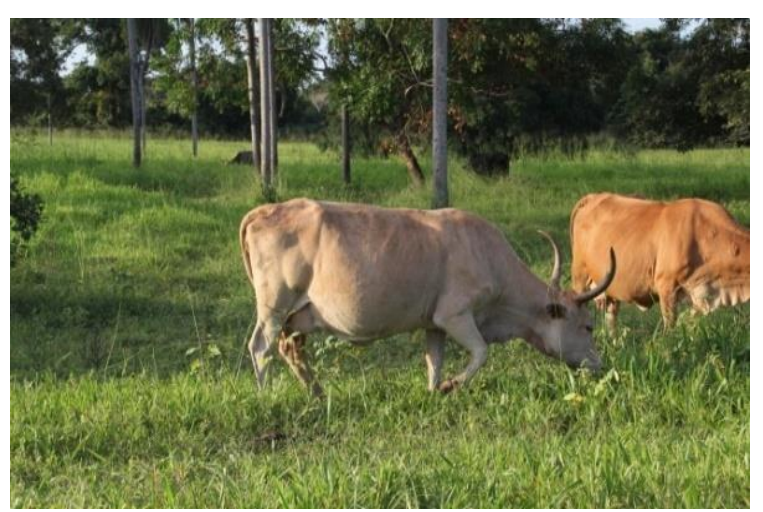

Foto 4. Vaca característica usada para produção de leite.
De modo geral, estas vacas apresentam uma produção de leite abaixo de $5 \mathrm{~kg} / \mathrm{animal} / \mathrm{dia}$. Esta produção está muito abaixo dos índices considerados satisfatório na exploração leiteira(Silva et al., 2012). O leite produzido é utilizado para fabricação de produtos na fazenda e para consumo dos funcionários e turistas. Todavia, a composição do leite produzido na fazenda ainda não foi determinada até este momento. Desta forma, seria interessante determinar a composição e qualidade do leite local. De modo geral, a composição química do leite, sobretudo da gordura, tem uma correlação com a qualidade da pastagem(Corradini et al., 2014). Assim, a determinação da composição do leite poderá possibilitar a fazenda a produzir produtos com maior valor agregado.

Segundo o proprietário da fazenda, em futuro próximo, vai ocorrer uma implementação de uma melhoria da produção de leite com a introdução de reprodutores da raça Gir (Foto 5).

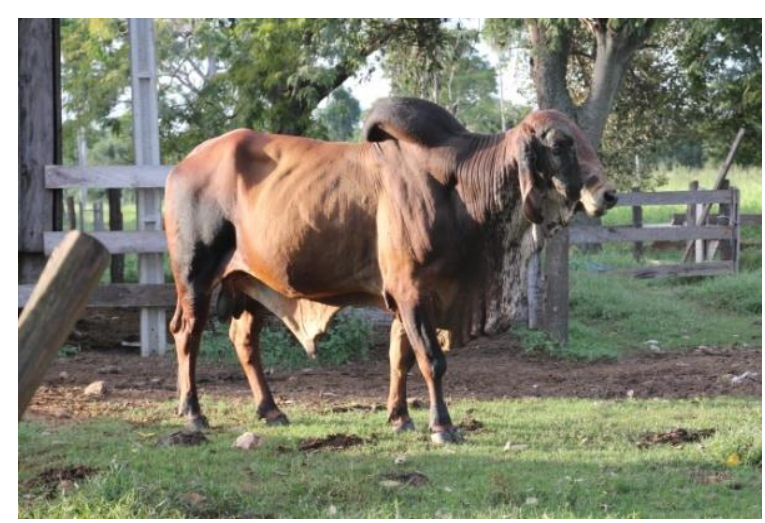

Foto 5. Reprodutor da raça Gir.

Com a introdução de animais da raça Gir, o proprietário espera aumentar a produção de leite, assim como melhorar sua rentabilidade. A raça Gir está bem adaptada às condições de clima quente e poderia proporcionar um aumento na produção de leite (Guimarães et al., 2002).

\section{Produção de carne}

A produção de carne bovina é realizada com uso quase exclusivo de bovinos da raça Nelore (Foto 6).

O sistema de produção é baseado na cria para os machos e recria, reposição de rebanho e engorda para abate para as fêmeas.

As fêmeas usadas na reprodução da fazenda alcançam um índice de fertilidade acima de $70 \%$. Este índice poderia ser considerado baixo em outras circunstâncias do Brasil (Vieira et al., 
2005). Por outro lado, este índice está acima de alguns dados observados no cerrado do Brasil (Batista et al., 2012). Assim sendo, os índices observados na Fazenda São José podem ser considerados satisfatórios para as condições de criação e do meio.

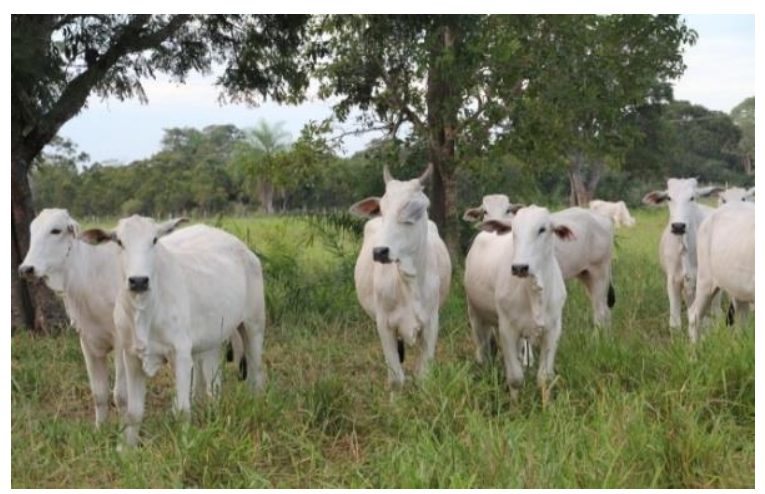

Foto 6. Animais Nelores da Fazenda São José.

Os bezerros logo após o desmame são vendidos para pecuaristas em função do elevado preço praticado na região (Foto 7).

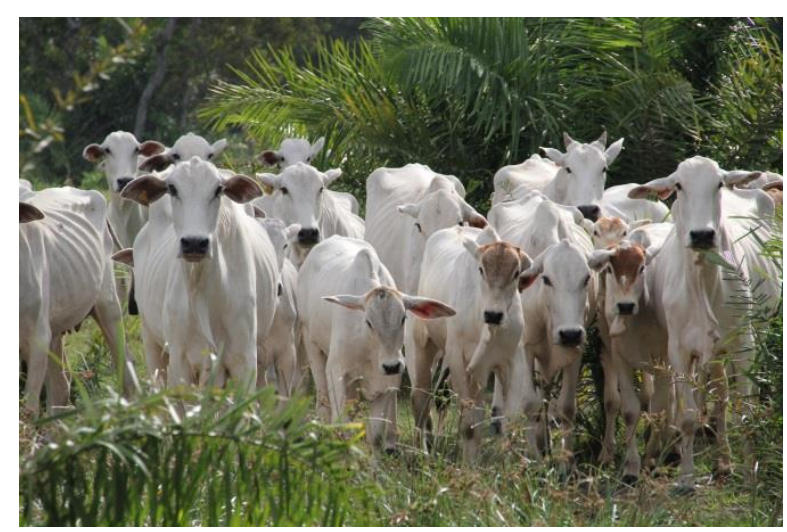

Foto 7. Vacas e bezerros da na fazenda São José.

De acordo com o pecuarista estes animais podem alcançar um ágio de até 30\% em comparação com o preço a arroba do boi terminado. Desta forma, é mais interessante ao pecuarista vender esses animais e reservar parte das pastagens às vacas e novilhas de reposição.

A qualidade do bezerro é determinada pela melhoria genética introduzida na fazenda nos últimos anos. Parte dos bezerros é gerada com o uso de técnicas modernas como a Inseminação Artificial em Tempo Fixo (IATF). A utilização de IATF numa determinada fazenda proporciona um aumento significativo na qualidade genética dos animais(Neves et al., 2010).

Por outro lado, além do uso de IATF o proprietário tem um sistema de fornecimento decreep-feeding durante o período de amamentação dos bezerros. Da mesma forma, esta técnica possibilita o desmame de bezerros mais pesados(Prado, 2010).

\section{Pastagens da fazenda São José}

$\mathrm{Na}$ fazenda São José as pastagens são constituídas essencialmente de três tipos de Brachiárias: Decumbes, Humídicula e Rhuzizienses (Foto 8).

De uma maneira geral, as três pastagens apresentam certas diferenças entre elas mesmas (Brito et al., 2003).

A Brachiaria decumbes foi semeada na fazenda onde as condições de solo e alagamento são melhores. Esta variedade de Brachiaria não suporta terra ácida e regiões alagadas. Deste modo, é normal que este capim esteja presente nos solos de melhor qualidade. Além disso, a composição e valor nutritivo da Brachiaria decumbens são superior aos demais Brachiarias. Por outro lado, a Brachiaria humidicula encontra-se implantadas nos solos menos férteis e onde ocorre, de modo mais frequente, alagamento na fazenda. Este capim apresenta baixo valor nutritivo, no entanto, suporta bem os solos mais pobres e regiões mais alagadas. Por último, a Brachiaria rhuziziense foi implantada numa região intermediária da fazenda, entre regiões mais altas e regiões mais alagadas. Este capim apresenta menor valor nutritivo em comparação a Brachiaria decumbens, mas suporta melhor solos mais ácidos e mais encharcados.
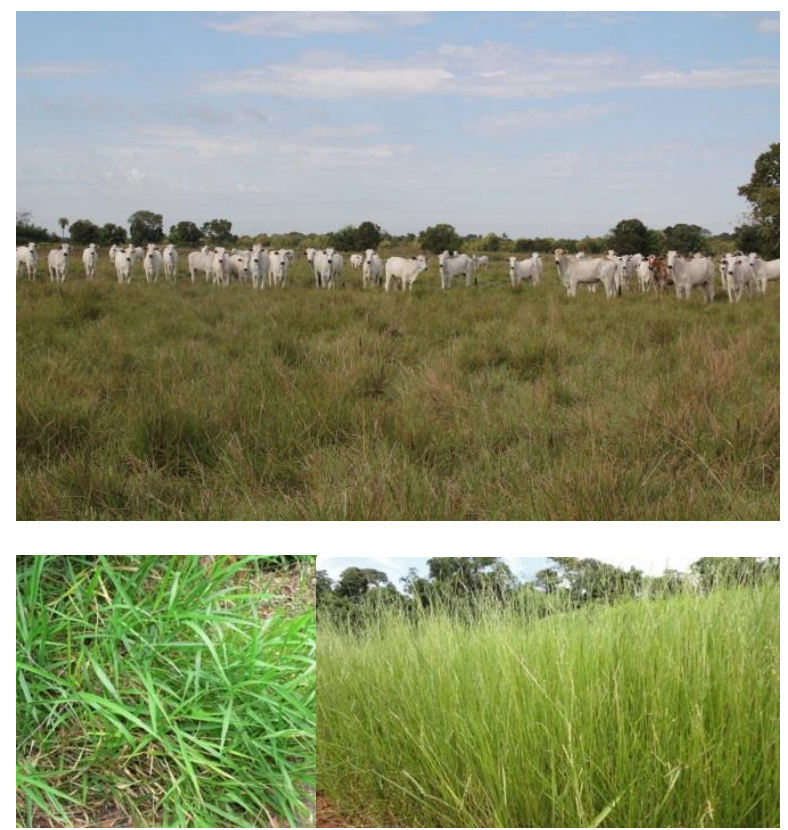

Foto 8. Decumbes, Humídiculae, Rhuzizienses. 
A escolha dos três tipos de pastagens para a fazenda nos parece bastante acertada. A topografia da fazenda não é uniforme e apresenta regiões onde ocorre anualmente alagamento. Deste modo, o produtor está agindo de modo correto na estratégia usada sobre o manejo das pastagens.

\section{Projeto do boi pantaneiro}

No último ano, o proprietário da fazenda está desenvolvendo um projeto interessante sobre o gado Pantaneiro. O gado Pantaneiro é característico da região (Foto 9).

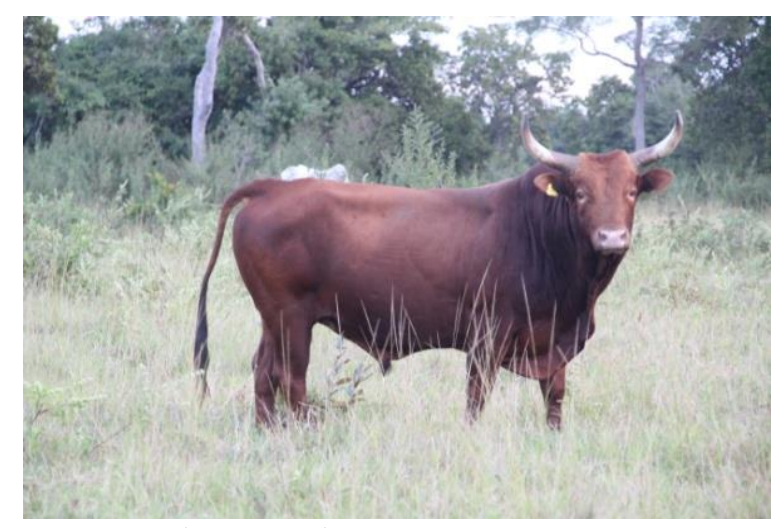

Foto 9. Boi pantaneiro

Este animal apresenta características interessantes no que concerne sua resistência e adaptação à região e baixa produção animal (Sereno, 2002).

\section{Agradecimentos}

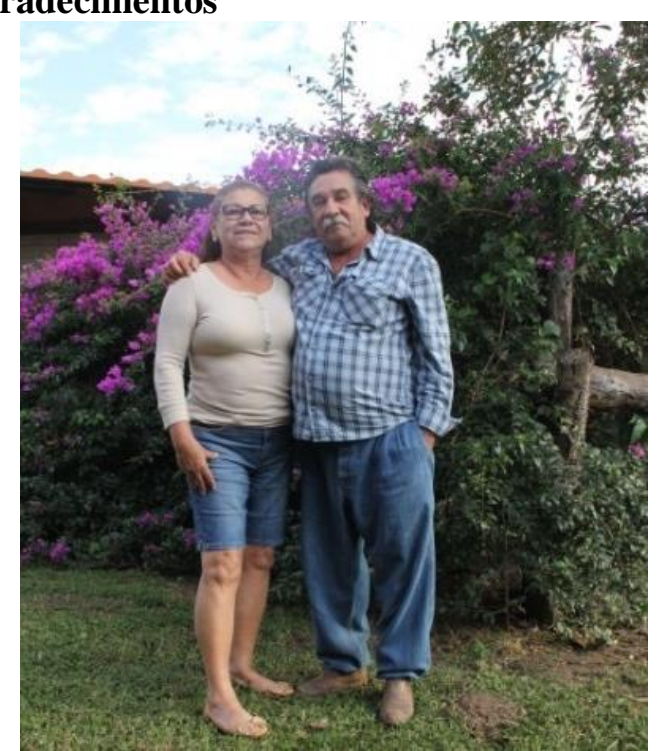

Foto x. Proprietários da Fazenda São José - Mato Grosso do Sul.

A equipe de trabalho expressa seus agradecimentos aos proprietários da Fazenda São
José, em particular ao Sr. João Idelfonso Pinheiro Murano e sua Sra. Vânia Alves Correa Murano, pela bela recepção e tratamento diferenciado a todos nós.

\section{Referências Bibliográficas}

ANUALPEC. (2014). Anuário da Pecuária Brasileira $\left(20^{\text {th }}\right.$ ed. Vol. 1). São Paulo, SP, Brasil: Instituto FNP.

Batista, D. S. N., Abreu, U. G. P., Bahiense, P., Filho, F. \& Nascimento Rosa, A. (2012). Índices reprodutivos do rebanho Nelore da fazenda Nhumirim, Pantanal da Nhecolândia. Acta Scientiarum. Animal Sciences, 34(1), 7176.

Brito, C. J. F. A., Rodella, R. A. \& Deschamps, F. C. (2003). Perfil químico da parede celular e suas implicações na digestibilidade de Brachiaria brizantha e Brachiaria humidicola. Revista Brasileira de Zootecnia, 32(6), 18351834.

Corradini, S. A. S., Madrona, G. S., Visentainer, J. V., Bonafé, E. G., Carvalho, C. B., Roche, P. M. \& Prado, I. N. (2014). Sensorial and fatty acid profile of ice cream manufactured with milk of crossbred cows fed with palm oil and coconut fat. Journal of Dairy Science, 97(12), 1-9.

Guimarães, J. D., Alves, N. G., Costa, E., Silva, M. R., Costa, F. M. J. \& Zamperlini, B. (2002). Eficiências reprodutiva e produtiva em vacas das raças Gir, Holandês e cruzadas Holandês $\mathrm{x}$ Zebu. Revista Brasileira de Zootecnia, 31(2), 641-647.

Neves, J. P., Miranda, K. L. \& Tortorella, R. D. (2010). Progresso científico em reprodução na primeira década do século XXI. Revista Brasileira de Zootecnia, 39(Especial), 414421.

Prado, I. N. (2010). Produção de bovinos de corte e qualidade da carne (Vol. 1). Maringá, Paraná, Brasil: Eduem.

Sereno, J. R. B. (2002). Uso potencial do bovino pantaneiro na produção de carne orgânica do pantanal. Paper presented at the Conferência virtual global sobre a produção orgânica de bovinos de corte.

Silva, J. J., Carvalho, D. M. G. d., Gomes, R. A. B. \& Rodrigues, A. B. C. (2012). Produção de leite de animais criados em pastos no Brasil. Veterinária e Zootecnia, 17(1), 26-36. 
Vieira, A., Lobato, J. F. P., Torres Junior, R. A. A., Cezar, I. M. \& Correa, E. S. (2005). Fatores determinantes do desempenho reprodutivo de vacas Nelore na região dos cerrados do Brasil Central. Revista Brasileira de Zootecnia, 34(6), 2408-2416.

Recebido em Maio, 25, 2015

Aceito em Junho 29, 2015
License information: This is an open-access article distributed under the terms of the Creative Commons Attribution License, which permits unrestricted use, distribution, and reproduction in any medium, provided the original work is properly cited. 